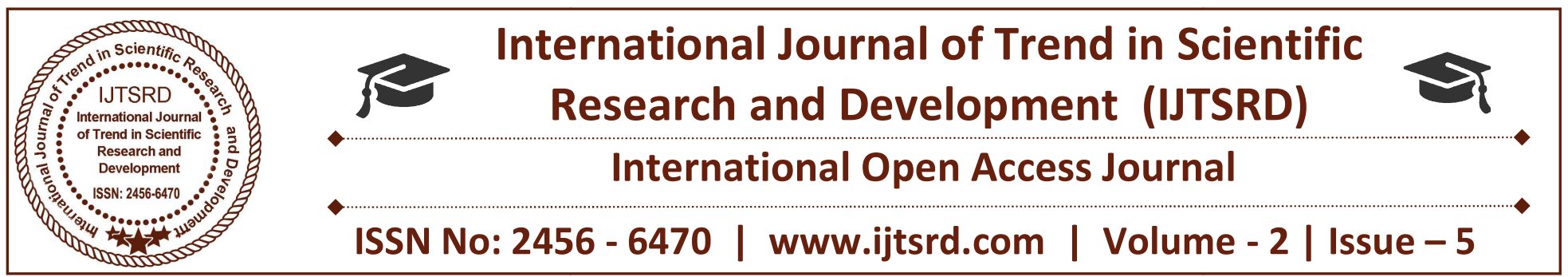

\title{
Antioxidant Activity of astaxanthin isolated from Charybdis Edwardsii (Leene and Buitendijk , 1949) from Pazhayar, Southeast Coast of India
}

\author{
Anandakumar Arunkumar ${ }^{1}$, Gnanakkan Ananthan ${ }^{2}$, Rajaram Murugan ${ }^{1}$ \\ ${ }^{1}$ Research Scholar, ${ }^{2}$ Assistant Professsor \\ Centre of Advanced Study in Marine Biology, Annamalai University, \\ Parangipettai, Tamilnadu, India
}

\begin{abstract}
Astaxanthin extracted from Red Crab Charybdis edwardsii was assayed for antioxidant activity viz., total antioxidant, reducing power, hydrogen peroxide radical scavenging assay, and DPPH free radicals scavenging activity. Final concentration of astaxanthin was quantified to be $49.05 \mu \mathrm{g} / \mathrm{g}$ using the standard astaxanthin. The antioxidant activity was found to be $60 \%$, hydrogen peroxide scavenging activity showed $89 \%$ inhibition, |whereas 1,1diphenyl-2-picrylhydrazl (DPPH) activity showed $86 \%$ of scavenging activity. Present investigation proves that the astaxanthin from $C$. edwardsii acts as a promising antioxidant source, which can be used in food, pharmacological and aquaculture sectors.
\end{abstract}

Keywords: Charybdis edwardsii, astaxanthin, antioxidant, $D P P H$

\section{INTRODUCTION}

The agricultural and food processing sectors face the problems of disposing waste products such as exoskeleton of crustaceans, thereby converting the waste material into the economic by products and it is common in the shellfish industries with the waste represents greater than $80 \%$ of landings. Thus, it has been estimated that solid waste from the crab industries is now in excess of a million $\mathrm{kg} /$ year in USA (Meyers et al., 1971). The processing of crustaceans such as shrimps and crabs generates large quantities of wastes in the form of head and body shells. These account for approximately $35-45 \%$ of the whole crustaceans weight (Khumallambam et al., 2011). The recovery of these valuable components from the waste would not only improve the economy for crustacean processors, but would minimize the pollution of crustacean wastes (Kuo et al.,1976). One possible use of this waste is as a source of carotenoids, protein and lipid for the diet of Salmonids raised in aquaculture. While the protein and lipids can be supplied from other sources, there is no source of the carotenoids astaxanthin other than from dietary crustacean. Carotenoids are a group of fat-soluble pigments occurring widely in nature. The aquatic animals such as crustaceans are known to contain various carotenoids and are considered as one of the important sources of natural carotenoids (Matsuno, 2001).There is currently considerable interest in the role of carotenoids in delaying or preventing degenerative diseases such as atherosclerosis, cancer, aging (Halliwell, 1997; RiceEvans and Burdon, 1994; Mathews-Roth, 1991) and eye diseases (Pratt, 1999; Kirschfeld, 1982). The antioxidant activity of astaxanthin has been reported to be 10 times stronger than that of other carotenoids, namely, zeaxanthin, lutein, canthaxanthin, and $\hat{a}$ carotene (Miki, 1991). Astaxanthin has been associated with reduced risk of diseases such as agerelated macular degeneration and ischemic diseases, effects attributed to its potent antioxidant activity (Tso and Lam, 1996). Astaxanthin is a substance best known for giving the pinkish-red colour to the flesh of salmonids (salmons and trouts), as well as shrimps, lobsters and crayfishes (Koller et al., 2014). Besides the colorant properties, astaxanthin displays a central role for the immune-system of these fishes and positively impacts their fertility (Koller et al., 2014). It is claimed to possess as much as 10 times the antioxidant potential of other carotenoids such as $\beta$ carotene, canthaxantin, zeaxanthin and lutein; and 100 times more that $\alpha$-tocopherol. Among the deep-water 
crab resources, the most promising is that of Charybdis edwardsii which gave a catch rate of 3500 $\mathrm{kg} / \mathrm{h}$ in try net hauls carried out off Mangalore and Ponnani (Silas, 1969). The aim of the present study is to evaluate the antioxidant activity of astaxanthin extracted from Charybdis edwardsii.

\section{MATERIALS AND METHODS}

\section{Collection}

The study animal Charybdis edwardsii was sourced from Pazhayar fish landing centre of (Lat 11' 21'22" $\mathrm{N}$; long $79^{\circ} 50^{\prime} 55^{\prime \prime}$ E) South east coast of India, Average weight of crab ranged from 25 to 36 grams. Crabs were washed in tap water to remove debris and soil then stored in deep freezer until further analysis.

\section{Extraction}

Astaxanthin content was determined according to the modified method of Tolasa et al. (2005) and Metusalach et al. (1997). Dried crab sample (30 g) was extracted thrice, with $50 \mathrm{ml}$ of acetone using incubating shaker for $48 \mathrm{hrs}$ at room temperature. After extraction, the samples were centrifuged at $4000 \mathrm{~g}$ at $4^{\circ} \mathrm{C}$ for $5 \mathrm{~min}$. To $/$ separate the waterinsoluble compounds, the acetone extracts of the sampleswere transferred to $40 \mathrm{ml}$ of petroleum ether in a 250 mlseparating funnel. Then, $100 \mathrm{ml}$ of distilled water containing $0.5 \%(\mathrm{w} / \mathrm{v})$ sodium chloride was added to the mixture. After continuous shaking by hand, approximately 20 minutes later, the petroleum ether layer was separated and transferredinto a $50 \mathrm{ml}$ volumetric flask.

\section{Quantification of astaxanthin}

The extracted astaxanthin is re dissolved in $3 \mathrm{ml}$ of acetone and read@468 nm.

\section{$\operatorname{AST}(\mu \mathrm{g} / \mathrm{g})=\underline{\mathrm{A} 468 \mathrm{~nm} \times \mathrm{V} \text { extract } \times \text { Dilution factor }}$ $0.2 \times \mathrm{W}$ sample}

Where, $\mathrm{A}$ is absorbance, $\mathrm{V}$ is volume of extract, 0.2 is the A468 of $1 \mu \mathrm{g} / \mathrm{g}$ of standard astaxanthin and $\mathrm{W}$ is weight of sample in grams. (Simpson and Haard, 1985).

\section{Total antioxidant activity}

Total Antioxidant Capacity (TAC) reagent was prepared by mixing of $7.45 \mathrm{ml}$ sulphuric acid $(0.6$ $\mathrm{mM}$ solution), $0.9942 \mathrm{~g}$ of sodium sulphate $(28 \mathrm{mM}$ solution) and $1.2359 \mathrm{~g}$ of ammonium molybdate (4 $\mathrm{mM}$ solution) in $250 \mathrm{ml}$ of distilled water. $300 \mu \mathrm{l}$ of isolated astaxanthin from the crab was dissolved in 3 $\mathrm{ml}$ of TAC reagent. Distilled water was used as blank. Absorbance of all sample mixtures was measured at $695 \mathrm{~nm}$. Gallic acid was used as standard to determine totalantioxidant activity (Khan et al., 2009).

\section{Reducing power}

$1.0 \mathrm{ml}$ of isolated astaxanthin from the crab was mixed with $2.5 \mathrm{ml}$ of phosphate buffer $(0.2 \mathrm{M}, \mathrm{pH}$ 6.6) and $2.5 \mathrm{ml}$ of potassium ferric cyanide (1\%). Reaction mixture was kept in a water bath at $50^{\circ} \mathrm{C}$ for 20 minutes. After incubation, $2.5 \mathrm{ml}$ of Trichloroacetic acid (10\%) was added and centrifuged at $650 \mathrm{rpm}$ for 10 minutes. From the supernatant, 2.5 $\mathrm{ml}$ solution was mixed with $2.5 \mathrm{ml}$ of distilled water and $0.5 \mathrm{ml}$ of ferric chloride $(0.1 \%)$. Absorbance of the solution was measured at $700 \mathrm{~nm}$ after every 10 minutes intervals up to 30 minutes. Increased absorbance indicated increased reducing power (Govindarajan et al., 2003).

\section{Hydrogen peroxide radical scavenging assay}

Hydrogen peroxide $(10 \mathrm{mM})$ solution was prepared in the phosphate buffer saline (0.1 M, PH-7.4). $1 \mathrm{ml}$ $(0.25 \mathrm{mg})$ of the isolated astaxanthin from the crab was rapidly mixed with $2 \mathrm{ml}$ of hydrogen peroxide solution. The samples were incubated at $37^{\circ} \mathrm{Cfor} 10$ min and the absorbance was measured at $230 \mathrm{~nm}$ against a blank (without hydrogen peroxide; Govindarajan et al., 2003). The percentage of scavenging of hydrogen peroxide was calculated using the following formula:

$\%$ Scavenging $=[$ Absorbance of control - Absorbance of test sample/Absorbance of control] $\times 100$

Where blank - phosphate buffer; control - hydrogen per oxide without astaxanthin; test

astaxanthin with hydrogen peroxide.

\section{1, 1-diphenyl-2-picrylhydrazl (DPPH) free radicals scavenging activity}

$1 \mathrm{ml}$ of test solution was mixed with $1 \mathrm{ml}$ of $0.1 \mathrm{mM}$ DPPH in methanol. The mixture was incubated in dark place for $30 \mathrm{~min}$ at $25^{\circ} \mathrm{C}$. After 30 minutes, absorbance wasrecorded at $517 \mathrm{~nm}$. (Shimada et al., 1992)The percentage of DPPH free radicals scavenging activity was calculated by following equation:

$\%$ Scavenging $=[$ Absorbance of control - Absorbance of test sample/Absorbance of control] $\times 100$

Where blank - methanol; control - DPPH in methanol without astaxanthin; test - astaxanthin with DPPH in methanol. 


\section{RESULTS AND DISCUSSION Quantification of astaxanthin}

The concentration of astaxanthin obtained from $C$. edwardsii was found to be $49.05 \mu \mathrm{g} / \mathrm{g}$. The present investigation was correlated with the earlier findings of Renata Aline dos Santos da Fonseca et al.(2011) and (Shahidi and Synowiecki, 1990).

\section{Antioxidant activity of astaxanthin standard and isolated astaxanthin}

Antioxidant properties of astaxanthin was evaluated since, astaxanthin possess the properties of free radical scavenging, anti-aging, anti-cancer, antiinflammatory etc. In the present investigation, total antioxidant property of astaxanthin was evaluated the antioxidant potential of $68 \%$ was found in astaxanthin standard, $60 \%$ was found in C. edwardsii but it is lower than that of gallic acid the standard drug i.e. $75 \%$ (Fig. 1). Sudhakar et al.(2011) recorded the total antioxidant activity ranged from $28.52 \%$ to $80.26 \%$ in $P$. Sanguinolentus crab shell chitosan sample. The present test was also correlated with the study of Soundarapandian et al.(2014) in which the total antioxidant activity was found to be 32 to $49 \%$ in soft and hard shelled crabs of C. Lucifera and $86 \%$ for Gallic acid.

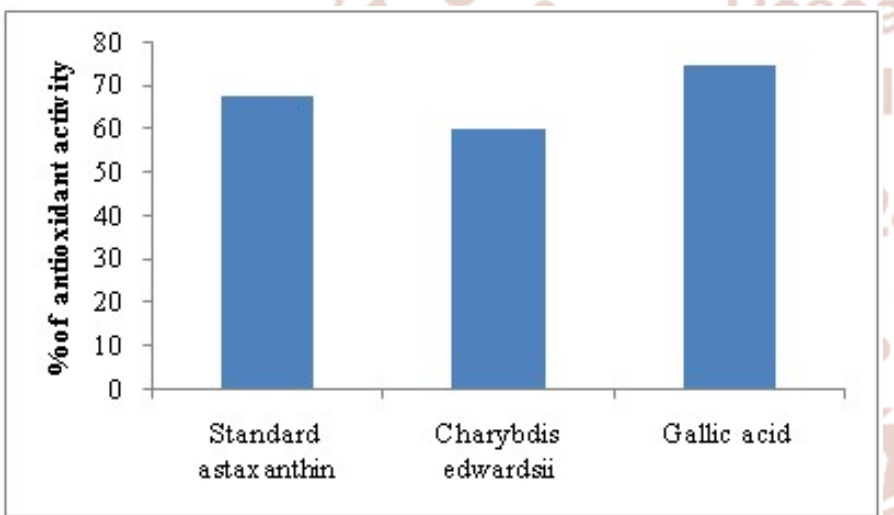

Figure1. Percentage of total antioxidant activity

\section{Reducing power assay}

The present investigation revealed the reducing effect of astaxanthin. Astaxanthin possess the ability to donate an electron to free radicals which leads to neutralization of the radicals. Reducing power was evaluated using ferric ions. There was increase in Optical Density for every 10mins in both the standard and the test samples. Due to increase in Optical Density, the result reveals the good reducing property.In reducing power assay, standard drug ascorbic acid was dominating agent that shows the maximum reducing ability i.e 0.06 for $10 \mathrm{mins}$ and
0.09 for 30 minutes, which is followed by astaxanthin standard that shows 0.05 for 10 mins and 0.08 for 30 minutes. The reducing ability of Red crab (C.edwardsii) was0.04 for 10 mins and 0.07 for30 mins. Thus, the result correlates astaxanthin as good reducing agents. Similar result was reported by Yen et al. (2014) and Soundarapandian et al. (2014).

\section{Hydrogen peroxide radical scavenging assay}

Hydrogen peroxide is a standard free radical compound which enhances the lipid peroxidase acitivity. During the present study, the ability of astaxanthin to scavenge hydrogen

peroxidewas assayed. The maximum activity of $89 \%$ inhibition was seen in ascorbic acid followed by standard astaxanthin of $68 \%$ inhibition. The scavenging activity of $67 \%$ (Fig. 2) was seen in $C$. Edwardsii (Red crab), these results further proves that astaxanthin has a good antioxidant property. The present study was corelated with the study of Soundarapandian et al. (2014).

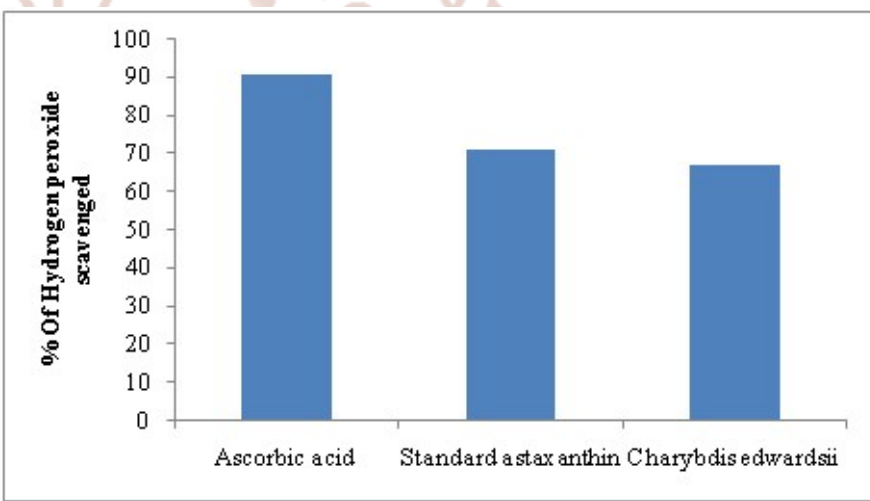

Figure2. Percentage of hydrogen peroxide scavenging assay

Scavanging ability on 1, 1- diphenyl-2picrylhydrazl radicals (DPPH) assay

DPPH is one of the stable free radical used for the assay of scavenging capacity of astaxanthin. The DPPH activity of standard Gallic acid was found to be $86 \%$. Standard astaxanthin had $79 \%$, where as $C$. edwardsii (Red Crab) possessed72\% (Fig. 3). 


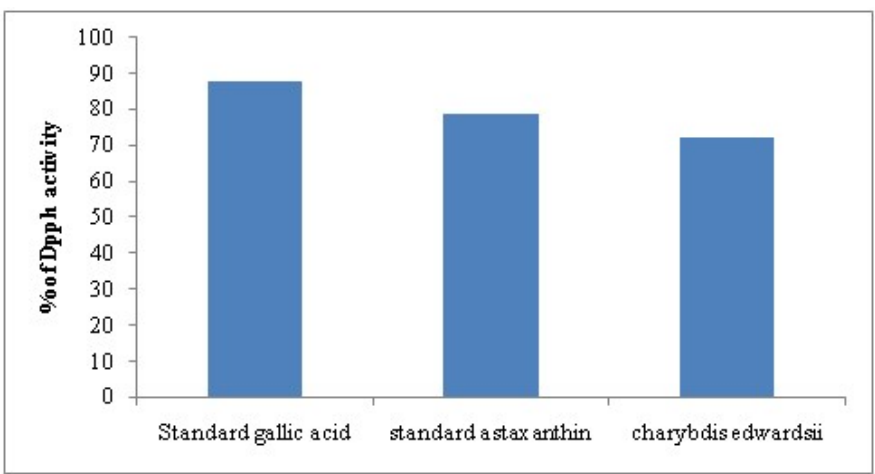

Figure3. Percentage of 1, 1- diphenyl-2picrylhydrazl radicals (DPPH) activity

Hence the results proved both Standard astaxanthin and astaxanthin extracted from Charybdis edwardsii possessed a good DPPH activity which predicted that DPPH would have picked up the electron in the presence of a free radical scavenger which is reflected as the percentage of DPPH activity. Similar result was reported by Yen et al.(2014) as it showed $82.9 \%$ scavenging activity. From the study, it has been proved that Charybdis edwardsii acts as a potent source of natural antioxidants, which can be used in the food and pharmaceutical sectors.

\section{ACKNOWLEDGEMENT}

The authors wish to thank the Dean and Director of CAS in Marine Biology and authorities of Annamalai University for providing facilities.

\section{REFERENCES}

1. Govindarajan, R., Rastogi, S., Vijayakumar, M., Shirwaikar, A., and Rawat, A.K.S., 2003. Studies on the Antioxidant Activities of Desmodium gangeticum. Bio Pharmal Bulle, 26 (10): 14241427.

2. Halliwell, B., Antioxidants and human disease: A general introduction. Nutr. Rev. 1997, 55, 544552.

3. Khan, M.A., Shahwar, D., Ahmad, N., Khan, Z. and Ajaib, M., 2009. Chemical constituents of Carissa opaca extracts and their evaluation as antioxidant and preservative in Edible Oils. Asian J Chem, 22 (1): 379- 388.

4. Khumallambam, M., Rama, S., Karuppannan, R. R., Manjabhat, S. N., 2011. Antioxidant activity of protein isolate obtained by the $\mathrm{pH}$ shift technique from hydrolyzed and unhydrolyzed shrimp processing discards. Journal of Aquatic Food Product Technology 20, 209-221. doi: $10.1080 / 10498850.2011 .559618$
5. Koller, M., Muhr, A., Braunegg, G. (2014). Microalgae as versatile cellular factories for valued products. Algal Research, 6, 52-63.

6. Kuo H.C., Lee, T. C., Kamata ,T., and Simpson, K.L., 1976. Red crab processing waste as a carotenoid source for rainbow trout. 47-51.

7. Mathews-Roth, M., Recent progress in the medical applications of carotenoids. Pure Appl. Chem. 1991, 63, 147-156.

8. Matsuno, T., 2001. Aquatic animal carotenoids. Fisheries Science 67, 771-783.

9. Metusalach, B., Brown, J. A. \& Shahidi, F. (1997). Effects of stocking density on colour characteristics and deposition of carotenoids in cultured Arctic charr (Salvelinus alpinus). Food Chemistry 59, 107-114.

10. Meyers, S. P., Rutledge,J. E. 1971. Economic utilization of crustacean meals feedstuffs. 43, 16,

11. Miki, W. Biological functions and activities of animal carotenoids. Pure Appl. Chem. 1991, 63 $141-146$

12. Pratt, S., Dietary prevention of age-related macular degeneration. J. Am. Optom. Assoc. 1999, $70,39-47$.

13. Rice-Evans, C. A., Burdon, R. H., Eds. Free radical damage and its control; Elsevier Science B.V.: Amsterdam, 1994.

14. Shahidi, F., Synowiecki, J., 1990. Isolation and characterization of nutrients and value added products from snow crab (Chinoecetes opilio) and shrimp (Pandalus borealis) processing discards. Journal of Agriculture and Food Chemistry39, 1527-1532.

15. Shimada, K., Fujikawa, K., Yahara, K., and Nakamura, T., 1992. Antioxidative properties of xanthan on the autoxidation of soybean oil in cyclodextrin emulsion. J. Agri. Food Chem, 40 (6): 945-948.

16. Simpson, B. K., and N. F. Haard., 1985."Characterization of the trypsin fraction from cunner (Tautogolabrus adspersus)." Comparative Biochemistry and Physiology Part B: Comparative Biochemistry 80 (3): 475-480.

17. Soundarapandian, P., Shyamalendu Roy and Varadharajan, D., 2014. Antioxidant Activity in 
International Journal of Trend in Scientific Research and Development (IJTSRD) ISSN: 2456-6470

Hard and Soft Shell Crabs of Charybdis lucifera (Fabricius, 1798). J. Aquacul Res Dev, 5 (7): 1-5.

18. Sudhakar, M., 2011. Biodiversity, resources, nutritional status and shell utilization of crabs from Cuddalore coast, Ph.D thesis, Annamalai University. 1-170.

19. TOLASA, S., S. CAKLI, and U. OSTERMEYER. "Determination of astaxanthin and canthaxanthin in salmonid." European food research \& technology 221.6 (2005): 787-791.

20. Tso, M. O., Lam, T.T., Method of retarding and ameliorating central nervous system and eye damage. U.S. Patent 5, 527,-533, 1996.

21. Yen, M. T., Yang, J. H., \& Mau, J. L. (2008). Antioxidant properties of chitosan from crab shells. Carbohydrate polymers, 74(4), 840-844. 